rev.relac.int.estrateg.segur.6(1):127-148,2011

\title{
EL DEBATE ENTRE PROSTITUCIÓN Y TRABAJO SEXUAL" Una mirada desde lo socio-jurídico y la política pública
}

\author{
Misael Tirado Acero, Ph.D ${ }^{* *}$
}

\section{RESUMEN}

Las implicaciones del trabajo sexual en el plano legal han tenido históricamente entre sus contradictores y seguidores debates representados en diversas corrientes jurídicas; tema que no resulta fácil de abordar teniendo en cuenta sus aproximaciones al plano de la moral, sumado a los borrosos límites con la ilegalidad. El Estado como institución tiene un rol determinante en las implicaciones que se ponen sobre la mesa al tratar el fenómeno social de la prostitución no solo en un contexto nacional, sino en un momento donde las leyes evolucionan de acuerdo con un panorama internacional

* Este documento presenta en algunos apartes los resultados de la investigación doctoral "Comercio Sexual", sumada al debate o controversia de la sentencia T-629 de 2010. La tesis doctoral reposa en la Biblioteca Central de la Universidad Externado de Colombia.

** Docente T. C. UMNG. Sociólogo de la Universidad Nacional de Colombia, con posgrados en Economía y Evaluación Social de Proyectos por la Universidad de los Andes. Doctor en Sociología Jurídica e Instituciones Políticas por la Universidad Externado de Colombia. Investigador en Biopolítica y Biojurídica y Derecho Comparado "BioeticsGroup", y Grupo Liderazgo, Sociedad y Bioética. Departamento de Humanidades, UMNG. Investigador Línea de Investigación Bioética y Derecho, Derecho Penal y Sociología Jurídica, Grupo Derecho Público, Facultad de Derecho, UMNG. misael.tirado@unimilitar.edu.co misaeltirado@gmail.com 
planteando no pocos dilemas frente al fenómeno que se desborda de los límites territoriales, siendo el caso de la sentencia T-629 de 2010 que abre la discusión en Colombia respecto al reconocimiento de la actividad de la prostitución como trabajo y sus implicaciones en las dimensiones económica y social.

Palabras Clave: legalidad, tráfico sexual, comercio sexual, prostitución, trabajo sexual, derechos humanos.

\begin{abstract}
The implications of sexual work in the legal arena have historically had their detractors and supporters, debates represented in various legal trends, an issue that is not easily addressed taking into account its approach to the moral plane, coupled with the blurred boundaries with illegality. The State as an institution has a decisive role in view of the implications that are put on the table when addressing the social phenomenon of prostitution not only in a local context, but in a time where laws evolve according to an international panorama, posing no few dilemmas to the phenomenon that goes beyond the territorial limits, being the case with ruling T-629 of 2010 that opens the discussion in Colombia regarding the recognition of the activity of prostitution as work and its implications in the economic and social dimensions.
\end{abstract}

Keywords: legality, sexual trafficking, sex trade, prostitution, sexual work, human rights.

\title{
RESUMO
}

As implicações do trabalho sexual na arena jurídica historicamente vêm apresentando opositores e simpatizantes, debates representados em diversas correntes jurídicas, trata-se de uma questão de difícil abordagem levando em consideração suas aproximações ao plano da moral, somado aos turvos limites com a ilegalidade. O Estado como instituição tem um papel decisivo, considerando as implicações que se evidenciam na abordagem do fenômeno social da prostituição, não só em um contexto nacional, mas também em um momento onde as leis evoluem de acordo a um cenário internacional, gerando uma série de dilemas perante o fenômeno que vai além dos limites territoriais, como é o caso da sentença T-629 de 2010, que abre a discussão na Colômbia com relação ao reconhecimento da atividade da prostituição como trabalho e suas implicações nas dimensões econômica e social.

Palavras chave: legalidade, tráfico sexual, comércio sexual, prostituição, trabalho sexual, direitos humanos. 


\section{INTRODUCCIÓN}

Los límites de la legalidad/ilegalidad en el ejercicio del trabajo sexual han enmarcado las discusiones que de trasfondo encierran la trasgresión de límites de lo que se ha considerado privado en su doble connotación, pues por una parte la exteriorización de la sexualidad no corresponde con la esfera de la intimidad, de lo que no saldrá nunca a la luz de lo público y, por otra parte, el trabajo sexual implica la trasgresión de lo privado, de la privación de la sexualidad.

Ahora bien, iqué sucede en el mundo contemporáneo en donde los límites de lo privado en su doble sentido se han delineado al margen de límites borrosos? Si bien el desarrollo del trabajo sexual no es contemporáneo, las discusiones que enmarcan su legalidad se han adelantado significativamente en un panorama histórico que encierra una serie de fenómenos que dan una orientación específica al fenómeno, como lo es la aceleración de la globalización, especialmente económica, que inevitablemente ha llevado a una aceleración del libre intercambio y en este contexto aparece acérrimamente una circulación masiva en el libre mercado mundial del sexo, lo cual implica necesariamente una movilidad de las personas prestadoras de servicios sexuales o, en otros casos, se hace uso del desarrollo tecnológico que permite una circulación global desde el plano de lo local, como lo que representa la pornografía con su rápida extensión en medios como Internet.

El nuevo panorama ha traído al presente viejas discusiones, especialmente en el plano de lo legal, que así mismo ha traspasado las fronteras y ha permitido el diálogo de diversas latitudes frente a un fenómeno que ha desembocado en una tipificación tan extensa que presenta nuevos retos a los legisladores a nivel global.

El presente texto se realiza con la intención de profundizar en el análisis de lo que representa especialmente la Sentencia T-629 de 2010 en el contexto legal colombiano, lo que implica de forma obligatoria una revisión al plano para lo cual, como ya se mencionó, las posibilidades que ha probado la globalización han llegado a límites que ahora es necesario estudiar detalladamente en la medida en que la realidad social en este fenómeno parece tomar ventaja rápidamente y más en el plano de lo legal, personificando una urgente necesidad de profundizar en su estudio, teniendo en cuenta sus implicaciones sociales y económicas a diversos actores que se mueven en el contexto del trabajo sexual de forma voluntaria como a las que no, realidad no tan evidente por su misma clandestinidad, pero que diversos estudios, como el realizado por Kara (2010), demuestran su magnitud y sus nocivas consecuencias para las personas víctimas de lo que se ha denominado tráfico sexual.

\section{¿Magnitud del problema?}

El comercio sexual no es un invento del mundo moderno, sus comienzos datan de tiempos remotos; por otra parte, su desarrollo y su categorización han ido cambiando, mutando de 
acuerdo con los contextos en los que se desarrolla, permitiendo establecer dentro de la categoría del comercio sexual, según Tirado (2010), la prostitución, el trabajo sexual/erótico, el turismo sexual, la explotación sexual de adultos, la pornografía infantil/adulta y la trata de personas con fines sexuales, categorías que por su misma esencia se desenvuelven generalmente en un plano de la economía ilegal o subterránea, lo cual implica de comienzo una dificultad en la cuantificación del fenómeno, aunque es necesario señalar que existen esfuerzos ${ }^{1}$ que intentan desarrollar una aproximación a la magnitud del fenómeno, sin que esto represente necesariamente un acercamiento veraz, pues como lo menciona Rubio (2010): “Un elemento recurrente, reflejo de la falta de rigor en el manejo de las cifras, son las supuestas estimaciones sobre el volumen monetario del negocio en miles de millones de dólares a nivel mundial. No sorprende que nunca se citen las fuentes de estos cálculos de novela, literalmente imposibles de realizar para un negocio informal, cuando no ilegal y clandestino, y centrado en transacciones en efectivo" (p. 35).

La carencia de información cuantitativa se presenta por cuenta del grado de clandestinidad y es un trabajo difícil, por no decir imposible, que estas cifras salgan reflejadas en las cuentas nacionales; aunque los recursos hagan parte del sistema económico, su contabilidad es precaria por diferentes factores como el manejo de las transacciones en efectivo que no son registradas y por su misma clandestinidad. Ante este panorama desalentador frente a la cuantificación del fenómeno, solo pueden tenerse datos de referencia que permitan de una forma más o menos cercana hacerse una vaga idea del desarrollo del fenómeno, aunque no se presenten datos oficiales como cualquier otro sector de la economía. Si algo se puede conocer es, como lo menciona Tirado (2010), que este es un negocio de "baja inversión", en el que se invierte poco y se gana mucho, sumado al creciente desarrollo del fenómeno, por ejemplo en Internet, en donde crece exponencialmente la tipificación del comercio sexual, creando incentivos para desarrollar aún más el comercio sexual.

Por otra parte, una de las grandes dificultades respecto a la cuantificación del fenómeno es la diversidad de servicios sexuales y, así mismo, su grado de diferenciación en este mercado, lo que representa una gran heterogeneidad en las cifras de ingresos. "Una muestra de 347 prostitutas que atienden en locales de características similares en 6 barrios relativamente homogéneos de Bogotá, reportaron en el año 2007, como promedio de lo que recibían por cada cliente, cifras que variaban entre US\$ 4 y US\$250, o sea una diferencia de uno a sesenta" (Rubio, 2010, p.37).

La prestación de servicios sexuales es tan amplia que necesariamente da cuenta de la demanda de estos, por lo cual las tarifas pueden variar según la región geográfica en donde se desarrolla la actividad, teniendo en cuenta las "preferencias del consumidor", como lo evidencian Levit y Dubner (2010) al sustentar que en periodos precedentes en Estados Unidos la práctica del sexo

1. Ver Kara, S. (2010), Tráfico Sexual, El negocio de la esclavitud moderna. Madrid: Alianza Editorial. 
oral representaba un alto precio sin desconocer el tabú que representaba esta práctica, pero cuando las actitudes sociales cambiaron su reducción en el precio fue significativo, por lo que la oferta (no necesariamente en el comercio sexual) de esta actividad sexual fue tan extendida y normalizada en las prácticas sexuales que redujo considerablemente su precio. Este es tan solo un caso que ilustra, por una parte, la heterogeneidad en las cifras que pueden presentarse por cuenta del mismo comportamiento de la oferta y la demanda y, por otra parte, revela la complejidad del estudio cuantitativo en el intento de realizar estudios comparativos debido a que las conductas sexuales $\mathrm{O}$, en otras palabras, "las preferencias del consumidor" pueden variar significativamente implicando una distorsión en su análisis.

Sin embargo, algunos estudios, como el desarrollado por Kara (2010), afirman que en el mundo aproximadamente para el año 2007 se encontraban bajo la denominación de esclavas sexuales 1'200.000 personas, en zonas como el Asia Meridional que llegaba a representar cerca del $28 \%$ del total de personas víctimas del tráfico de personas a nivel mundial, seguido de zonas como el Asia Oriental y el Pacífico con cerca del 26\%. "La tasa de crecimiento actual es muy inferior a la tasa de hace quince años, cuando el tráfico sexual explosionó coincidiendo con la expansión de la globalización económica" (Kara, 2010, p.46). Estas cifras podrían ser mayores, pues no se cuentan las personas que de forma voluntaria entran a formar parte del comercio sexual a nivel mundial.

Desde la perspectiva económica el fenómeno supone grandes retos en su estudio, dado que estas personas representan un modelo de producción en el que la "mano de obra" trasciende las fronteras nacionales basándose en la movilidad de esta mano de obra desde países que generalmente presentan niveles de desarrollo bastante pobres, como el caso de países de África o América Latina, obstáculo aún mayor en su seguimiento en términos de ingresos monetarios y número de personas prestadoras de servicios sexuales.

Sin embargo, la realidad del comercio sexual no puede ocultarse ante la ausencia de una estandarización numérica, por lo cual siendo un fenómeno social que está presente en las sociedades es función de los legisladores prestar atención a su desarrollo. Tanto en el contexto nacional como internacional se han promulgado diversidad de estilos jurídicos que han abordado el fenómeno; para el caso colombiano, se fija actualmente la atención en la sentencia T 629 de 2010, emitida por la Corte Constitucional, en la cual se analiza de qué forma se contempla el ejercicio de la prostitución y qué impedimentos se esgrimen frente a esta. También se considera y se reconoce, según la Constitución, la ley, la doctrina, la jurisprudencia y las normas internacionales, cómo la prostitución es una actividad laboral más, que está compuesta por un contrato de trabajo y de garantías mínimas en su ejercicio, marcando de una forma más abierta la distinción entre lo legal y lo ilegal, reconociendo la libertad de los ciudadanos en elegir su forma de sustento además de castigar los casos en los cuales se ejerce coacción directa para el ejercicio de la prostitución, violando múltiples derechos de la población que es víctima de la explotación sexual con fines comerciales, tanto de población adulta como de niños y niñas. 
Este es un tema muy tenso y preocupante entre la sociedad y los órganos del Estado, especialmente en cuanto a su normatividad y adecuación típica o no típica dentro del derecho penal. Es decir, rechazo y reproche de las actividades de la prostitución según el ordenamiento jurídico imperante o según las concepciones morales de la sociedad. De igual manera, es un punto de tensión respecto de los derechos de las personas inmersas en el trabajo sexual, no discriminación, y la sociedad como colectividad definitoria o no de las conductas delictuosas.

Las discusiones que se han dado en torno al ejercicio del trabajo sexual han girado en una órbita de su aceptación y su negación, permitiendo postular varias perspectivas que tratan temas referentes a sus efectos e implicaciones a nivel social y jurídico. Podemos, de manera muy general, mencionar las siguientes: (i) el individuo que ejerce la prostitución frente a la sociedad, implicaciones presentes y futuras; (ii) el Estado como ente interviniente en el ejercicio de la actividad, en interés de la salud y el orden público; (iii) los postulados del derecho internacional y del derecho comparado, respecto al trabajo sexual; (iv) la normatividad jurídica nacional e internacional referente a la prostitución y su ejercicio (modelos normativos); (v) los Derechos Humanos frente a las personas que desarrollan esta actividad.

\section{El individuo que ejerce la prostitución frente a la sociedad, implicaciones presentes y futuras}

Cuando se hace referencia a la prostitución, al trabajo, al comercio, a la explotación sexual y a todas sus manifestaciones, necesariamente nos estamos refiriendo de forma implícita a la sexualidad, a sus nuevos discursos, a sus manifestaciones, a sus encuentros y desencuentros, a sus tabúes y prohibiciones y a sus nuevos límites en un marco de lo privado/publico, en una lucha permanente por proteger, pero develar, en un contexto que requiere hacer explícito, pero otra parte censura.

En todas las épocas históricas, en términos de Maffesoli, se presentan ideas obsesivas adoptando diversas formas en toda la gama de la expresión social. "Una de estas ideas obsesivas, que transversalmente recorre todas las civilizaciones, es la vida moral, en el sentido simple del término" (Maffesoli, 1994, p.103). Aunque el mundo presenta actualmente una gran explosión de manifestaciones que divergen de una moral centralista y reguladora del universo social, no implica que no existan unos códigos específicos que permiten la integración social a través de la divergencia.

Estos códigos unificadores ponen de manifiesto las disidencias del mundo moderno en donde, a pesar de una propagación de la sexualidad públicamente aceptada, existen códigos que liberan las vacilaciones de lo deseable y aceptable frente a la censura y estigma de otro tipo de conductas sexuales del mundo contemporáneo. En el comienzo de su libro Sexo Global, Dennis Altman muestra la diferenciación de la percepción frente a los escándalos sexuales que sacudieron dos gobiernos muy diferentes; por una parte, mientras el presidente Clinton se expuso ante 
la opinión pública por sus escándalos sexuales el ex primer ministro Anwar Ibrahim fue arrestado y golpeado tras haber sido acusado de varios delitos sexuales; dos hechos que revelaban aspectos propios de la intimidad y de la sexualidad fueron percibidos diametralmente diferentes, pues mientras a Clinton se le presentaron problemas de imagen y de manejo de opinión pública, a Ibrahim le produjo la sentencia a pagar varios años de cárcel; sin embargo, prevalecen códigos unificadores que permiten establecer la privación de lo privado, una conducta moral unificadora que no permite la trasgresión de algunos aspectos de la vida pública, efecto en gran medida de lo que ha llamado Altman (2006) globalización, llevándonos a cambios que simultáneamente conducen a la homogeneidad, pero así mismo a una mayor desigualdad.

Por otra parte, el nuevo escenario mundial ha mostrado un marco de oportunidades de desarroIlo individual en contraposición a los valores impuestos por el poder de la reproducción de valores potenciados por las nuevas tecnologías de la información; no han logrado representar una represión de las nuevas identidades contemporáneas, en contraposición o como respuesta a los desencantos de los grandes ideales de igualdad, abriendo paso a la manifestación de las políticas de la diferencia, es decir, el cuerpo se ha transformado con más fuerza como agente político que rechaza los modelos únicos tradicionalmente concebidos.

Para puntualizar es necesario señalar el caso de la prostitución a nivel global. Se ha creído que en los países de menores ingresos es en donde puede existir una oferta especialmente numerosa de personas dispuestas a ofrecer servicios sexuales, o mejor, están dispuestas a ofrecer su mano de obra a un menor precio; de tal manera se relaciona de forma directa el ejercicio del trabajo sexual dadas las condiciones precarias de los ingresos, pero Rubio (2010) demuestra cómo existe una relación directa entre tendencias de liberación femenina entendida desde el acceso al mercado laboral de las mujeres y el crecimiento del ejercicio del trabajo sexual, lo cual violaría los supuestos tradicionales de la carencia de ingresos como factor determinante para el ejercicio a este tipo de trabajo. El autor señala que esta tendencia se presenta principalmente en países en donde la liberación femenina o la incursión al mercado laboral femenino ha tenido más fuerza, por lo cual se podría entender el trabajo sexual como una manifestación de la liberación femenina, como una fuente de ingresos que permite cortar la dependencia económica, siendo entonces el cuerpo un vehículo político de reivindicación a pesar de las discusiones feministas de corte marxista que entiende la prostitución como una nueva forma de esclavitud.

\section{El Estado como ente interviniente en el ejercicio de la actividad, en interés de la salud y el orden público}

Ante las divergencias morales propias que implica el desarrollo del trabajo sexual los Estados no han sido ajenos al fenómeno, postulando sus diversas posiciones que enmarcan sus visiones morales frente al fenómeno y consecuentemente con el crecimiento del fenómeno los Estados han extendido sus preocupaciones, manifiestos en una carrera legislativa alrededor de la 
prostitución, unos en una vía prohibicionista y otros en una vía legalista, frente a lo cual Rubio (2010) presenta el Índice de Legalidad de la Prostitución ILP, permitiendo observar las tendencias legislativas a nivel global, en las cuales las sociedades más liberales tendiendo hacia la legalización tienen un indicador cercano a 1, mientras que los países más restrictivos muestran un resultado cercano a 0 . Según los resultados los países europeos muestran una tendencia predominantemente legalista, mientras países del oriente como China, Taiwan o Thailandia son primordialmente restrictivos.

En el caso colombiano, en los últimos años se ha presentado una tendencia que se orienta hacia la legalización, especialmente en Bogotá, ciudad en la cual en los últimos años se ha comenzado a gestar una senda reglamentarista a través de múltiples decretos que han reconocido la existencia del fenómeno.

Por otra parte, la reglamentación del trabajo sexual en los diversos países se ha gestado por cuenta del creciente desarrollo de la explotación y tráfico sexual que se da en el marco de un comercio sexual cada vez más extendido en el mundo, dadas las condiciones de la globalización que facilita la interconexión con lugares que antes parecerían inalcanzables; de tal forma se ha gestado importante el fenómeno de la explotación que es entendida por Tirado (2010) como un concepto "... que aparece en la época de los setenta, como parte del discurso feminista, que intenta explicar la subordinación de las mujeres a través de categorías marxistas." (p. 67), además del creciente tráfico de personas con fines comerciales, que maximiza las ganancias de los empresarios del sexo bajo la figura de la coerción y el engaño.

La India es uno de los casos más representativos, siendo uno de los países que mayores cifras de personas caen bajo las redes del tráfico sexual, en gran medida por el desprecio que se tiene por la figura femenina, incluso en sus núcleos familiares, como lo señala Manier (2007) al investigar la carente falta de mujeres en este país que llega a ser 100 millones menos que la población de hombres, por cuenta del desprecio hacia las mujeres vivido en este país y en su continente dadas las condiciones predominantemente machistas, en términos del autor: “... El continente desprecia a las niñas hasta el punto que una parte de la población las elimina físicamente antes de que nazcan" (Manier, 2007, p.15). Bajo este panorama, el tráfico sexual, especialmente femenino, es un negocio rentable para los comerciantes que necesitan de las mujeres mientras su tierra las desprecia. Este no necesariamente es el único caso, como lo anota Kara (2010) al investigar el tráfico sexual en países como Moldavia, en países de la antigua Unión Soviética, Albania, Los Balcanes, Tailandia, entre otros tantos, los cuales presentan alarmantes cifras de tráfico de personas por cuenta de la propia discriminación de la cual son víctimas las mujeres en sus sitios de origen, convirtiéndose en un negocio rentable para algunos empresarios del sexo que someten a estas mujeres sexualmente con fines comerciales.

Frente a este panorama, es necesaria la intervención de los Estados de forma articulada aunque, como lo señala Kara, existen 4 problemas que impiden la eliminación del tráfico sexual: 
1) Las organizaciones dedicas a combatir esta problemática carecen de recursos suficientes, además de su escasa articulación internacional, 2) las leyes en los países, especialmente los afectados con el tráfico sexual son laxas, además de no existir una fortaleza institucional que dé cabal cumplimiento a la normatividad, 3) existe una carencia de análisis económicos que permitan establecer puntos estratégicos de acción y, 4) el fenómeno no se ha estudiado lo suficiente, lo que impide la identificación de sus causas con exhaustividad que permita combatir el tráfico sexual.

\section{Los postulados del derecho internacional y del derecho comparado, respecto al trabajo sexual}

La sentencia emitida por la Corte Constitucional en 2010 para el caso colombiano da cuenta de los principios fundamentales bajo los cuales se determinan las condiciones de legalidad del trabajo sexual, por lo menos en el caso tutelado, el cual expone la situación de una mujer que ejercía el trabajo sexual y fue despedida de su trabajo por encontrarse en estado de embarazo, por ello la mujer exige se tengan en cuenta sus derechos laborales, siendo trabajadora sexual, actividad económica que no se había reconocido como tal por el Estado colombiano. El problema jurídico puede llegar a ser bastante complejo por las implicaciones a las cuales conduce, pero en resumen la Corte Constitucional plantea el principal problema jurídico bajo la pregunta:
“¿Una persona que se dedica a la prostitución, en particular cuando se en- cuentra embarazada, tiene la misma protección constitucional que otro tipo de trabajadoras, para efectos de su estabilidad laboral, derechos a la seguri- dad social y, en definitiva, salvaguarda del mínimo vital suyo y del que está por nacer?" 2 .

Antes este planteamiento, son esgrimidos por la Corte Constitucional los siguientes argumentos para evidenciar la legalidad del trabajo sexual en un marco constitucional.

Igualdad. Es necesario reconocer que en la igualdad es donde se cimientan los fundamentos del Estado colombiano bajo el principio de igualdad formal o igualdad ante la ley, que supone que el Estado debe garantizar una prohibición tajante a cualquier tipo de discriminación por cuenta de los rasgos propios de su identidad como raza, sexo, religión o filiación política o ideológica. Sumado a este principio el Estado debe garantizar una dimensión promocional de la igualdad material o de trato, orientado a superar la desigualdad a la que han sido expuestos grupos minoritarios.

2. Véase, Corte Constitucional. Sentencia T- 629 de 2010 (M.P. Juan Carlos Henao Pérez). 
La igualdad se fundamenta bajo las siguientes características primordiales: (i) en el goce de los derechos, es decir, igualdad en la ley; (ii) material en el mínimo de condiciones para vivir; (iii) prohibición de la discriminación, uniformidad de trato; (iv) carácter relacional ${ }^{3}$, es decir, un trato igual a lo igual y un trato desigual a situaciones desiguales. La igualdad debe ser real y efectiva, por parte de las autoridades públicas y de la sociedad, en correspondencia con los fines esenciales del Estado Social y Democrático de Derecho.

Derecho comparado. Analizando los diferentes aspectos de cada uno de los modelos normativos, se puede establecer que: (i) Estados Unidos (a excepción de Nevada y algunos otros) son de tendencia prohibicionista; (ii) son abolicionistas Inglaterra, Italia y Francia; (iii) Alemania, Holanda y Nueva Zelanda conceptualizan el modelo normativo reglamentarista.

La sentencia en análisis proporciona unas conclusiones finales, respecto al derecho comparado, que comprenden:

"Pues bien, del estudio de varios regímenes jurídicos de los Estados se establecen como conclusiones principales frente al tema (...): i) En general no hay infracción para el ejercicio individual de la prostitución, aunque restan excepciones para ciertas formas de desempeño, que aún son sancionadas. ii) Si bien es evidente la crisis del modelo abolicionista, esto empero no va acompañado de un consenso sobre la necesidad de atribuir carácter de trabajo a la prostitución. Y al contrario, en todos los países, salvo en Holanda, Alemania y Nueva Zelanda, la ausencia de reconocimiento jurídico de la profesión impide a las mujeres en prostitución disponer de una cobertura social completa (...). Dado que la prostitución no constituye una infracción en sí misma, su ejercicio pertenece de modo significativo a la economía subterránea y las mujeres que ejercen la prostitución viven al margen de la legalidad. iii) (...) Sin embargo, el rendimiento de la prostitución se somete a tributación en la mayoría de los países porque el hecho generador del impuesto es independiente de la legalidad de la actividad. iv) Es finalmente regla universal la prohibición y la persecución severa de la prostitución forzada de menores de edad y el tráfico de personas para el desarrollo de tal actividad"4.

Derecho Internacional. La tendencia a nivel Internacional es un modelo de corte prohibicionista, debido a la comisión de delitos sobre trata de blancas y la explotación de seres humanos a fin de obtener numerosos beneficios económicos.

3. Véase, Corte Constitucional. Sentencia T-152 de 2007 (M.P. Rodrigo Escobar Gil; 5 de marzo de 2007).

4. CORTE CONSTITUCIONAL, Sentencia T-629 del 13 de agosto de 2010, M.P. Juan Carlos Henao Pérez, pp. 27 y 28. 
Derecho europeo. Hace visible todos los modelos descritos: abolicionista, prohibicionista y reglamentarista, según sea el ámbito desde el cual se analice el fenómeno, como degradación humana relacionada con la delincuencia organizada, como condición frente a la cual los Estados europeos asumen responsabilidades y también como opción económica digna, incluso de protección judicial.

El derecho colombiano. En Colombia se toman las diversas características de cada modelo normativo (prohibicionista, abolicionista y reglamentarista), en cuanto se compone de una tendencia mixta o ecléctica, estableciendo todo tipo de medidas.

Derecho Penal. Dentro de la sentencia se mencionan un conjunto de normas encaminadas a sancionar aquellas conductas que atenten contra la libertad, integridad y formación sexual. Pero se debe ahondar, dentro de este conjunto normativo-penal, en el Artículo 213 del Código Penal, analizado en su constitucionalidad por la Sentencia C-636 de 2009, que estableció según las consideraciones de la Corte Constitucional, bajo parámetros internacionales, que: (i) la punición de todas las conductas destinadas a llevar a otro al ejercicio de la prostitución, sea que se obligue por la fuerza o se convenza por la inducción, sea que este actúe sobre personas sin capacidad de discernir o decidir, o frente a aquellas que pretenden actuar libremente; (ii) la punición no alcanza a la persona que de manera directa, de forma autónoma e individual, ejerce la prostitución; (iii) tampoco la punición contempla una sanción para las actividades ejercidas por los dueños de los locales comerciales donde la misma se practica.

Respecto a las disposiciones contempladas en el derecho penal, podemos concluir que esta parte del ordenamiento jurídico nos presenta una tendencia prohibicionista.

Derecho Policivo. Este conjunto de normas jurídicas plantea que la prostitución es un fenómeno social reglado, considerando un modelo reglamentarista que va dirigido a proteger la salud pública, el orden social, la convivencia entre quienes practican la prostitución y el resto de la colectividad, así como en definir las zonas o ubicación geográfica que permita el ejercicio de esta actividad, tomando como fundamento una reducción en el impacto que pueda generar.

Podemos observar que, en un punto del análisis de los dos ordenamientos jurídicos mencionados, se trata de un:

"sistema dispar que bien refleja las tendencias de la tradición jurídica frente a la prostitución. Medidas prohibicionistas, abolicionistas y reglamentaristas que operan al mismo tiempo, que no siempre dialogan ni se miden según sus resultados, esto es según el nivel de protección o desprotección de los derechos y de bienes que se afectan (de los trabajadores sexuales, de sus familias, de la ciudadanía, del espacio público, de la convivencia ciudadana, de los propietarios de los establecimientos). En todo caso, se configura así un 
régimen animado por la pretensión de corrección del Derecho, que actúa en pos de la dignidad ${ }^{5}$ y la libertad y de la eliminación de cualquier forma de explotación humana y de la mujer. De allí la tensión permanente entre la tendencia a erradicar la actividad a través de la prohibición y la punición de conductas y la que apunta por otro lado a reconocer derechos para las personas que la ejercen y a legalizar explícitamente la actividad en general"6.

Ahora bien, con las consideraciones anteriores, la Corte plantea si la actividad a la prostitución es o no lícita, concluyendo que es lícita. Sin embargo, le determina unos límites que son: las normas imperativas y las buenas costumbres. Por normas imperativas no hay problema alguno, como ya se analizó; el problema radica respecto a las buenas costumbres. Las buenas costumbres deben observarse desde el ordenamiento jurídico imperante, es decir, desde la normatividad que fue realizada bajo la participación directa e indirecta del pueblo; por lo tanto, las buenas costumbres es moral y la moral constitucional y legal.

Así se concluye que la prostitución es una actividad con objeto lícito, pero con límites estrechos. Lícita porque no está prohibida, pero los límites están trazados por el ordenamiento jurídico en diferentes niveles: derecho penal, urbanístico, sanitario, límites que determinan y reducen el ámbito o la esfera de la libertad, pero que no la suprimen.

En este orden de ideas la prostitución es una actividad económica reconocida por el derecho: se sustenta como actividad comercial, pues tiene registro (denominado acompañamiento y masaje) en el Código Universal para clasificar las distintas actividades económicas que se desarrollan; por lo tanto, están llamados a proporcionar tributos al Estado.

Esta es una actividad lícita, que admite ser ejercida por cuenta propia y por cuenta ajena. Cuando es por esta segunda, se generan unas relaciones entre el dueño del local y quien realiza la actividad sexual o quien presta los servicios sexuales, produciendo bajo el principio de la primacía de la realidad la configuración de los elementos del contrato de trabajo, con todas sus consecuencias o efectos jurídicos, entre ellas su incumplimiento.

Para finalizar, se lleva a cabo un análisis del estado de embarazo en el ejercicio de la actividad sexual-prostitución. Se determina que la persona en este estado es considerada, según la Carta Política, un sujeto de especial (reforzada) protección constitucional y que no debe discriminársele por ejercer dicha actividad; más aún, cuando la Constitución Nacional le brinda derechos y garantías para el ejercicio de su autonomía e independencia personal.

5. Corte Constitucional. Sentencia T-881 de 2002 (M.P. Eduardo Montealegre Lynett; del 17 de octubre de 2002) que establece tres significados o conceptos respecto a la dignidad humana: (i) vivir como se quiere; (ii) vivir bien; (iii) vivir sin humillaciones.

6. Óp. Cit., Sentencia T-629 de 2010, p. 45. 
Por otro lado, en la sentencia no se decreta el reintegro, porque el Estado no quiere auspiciar la prostitución, pero si el legislador considera que si lo quiere reintegrar a futuro, pues no se encuentra impedimento alguno.

Teniendo en cuenta este estudio de la Corte Constitucional, se declara procedente la tutela porque es sujeto de especial protección constitucional, como mujer y prostituta, y se declara que prospera porque se acreditan los elementos que constituyen el contrato de trabajo y se verifica que fue despedida sin justa causa, por su estado de embarazo. Se reconoce la indemnización, pero respecto a las demás obligaciones laborales habrá que acudir a las instancias ordinarias laborales porque existe duda de continuidad.

\section{La normatividad jurídica nacional e internacional referente a la prostitución y su ejercicio (modelos normativos)}

El tema de la prostitución ha sido tratado desde el derecho mediante tres modelos tradiciona$l e s^{7}$ : (a) Prohibicionista, que define que todas las conductas relacionadas con el tráfico sexual de la persona prostituida, y esta misma, son conductas punibles. Por atentar contra los bienes jurídicos protegidos como son la moral pública y las buenas costumbres, el cliente es considerado víctima; (b) el modelo abolicionista elimina no el hecho en sí de la prostitución, sino la aceptación de su existencia y, por tanto, de regulación normativa. Se fundamenta en la protección de la familia y de las mujeres. De tal manera que excluye la punición de la actividad individual; sin embargo, persigue su entorno, es decir, la organización de negocios en cuanto a la prestación de servicios sexuales y, (c) el modelo reglamentista reconoce la prostitución como un mal social que, al no poderse combatir, debe ser regulado frente a los efectos perniciosos relacionados con la salud, la convivencia y las buenas costumbres; es decir, que este modelo pretende cuidar al cliente y, de forma indirecta, a aquellos que viven la prostitución sin ejercerla, pues permite la explotación de establecimientos comerciales relacionados con esta actividad sexual y se facilita el contacto entre trabajador o trabajadora sexual y clientes. De manera eventual se puede considerar, dentro de los cuatro tradicionales modelos normativos, el laboral (Tirado, 2010), en el que la prostitución se valora como un trabajo más, al cual deberían aplicarse los mismos instrumentos para proteger a los trabajadores industriales de las posibles violaciones o abusos de sus derechos.

\section{Los Derechos Humanos frente a las personas que desarrollan esta actividad}

Teniendo como punto de partida unos códigos de comportamiento universales o, en otros términos, de una ética universal, surge la idea de derechos humanos como derechos aplicables a la condición humana, logrando adquirir un importante protagonismo en las últimas décadas,

7. En estos modelos, de manera transversal, se conciben como conductas punitivas o delitos todo tipo de prostitución forzosa. 
señalando una ética de tipo universal manejado en los discursos circundantes a la cotidianidad y consolidándose una tendencia a expresar la inconformidad y protestar en el lenguaje propio de lo que implican, permitiendo a su vez una visibilización de actores que reclaman por la dignidad humana y por el derecho a la vida.

Estos sujetos emergentes, como campesinos, obreros, desplazados, indígenas, recicladores, entre otros, comienzan a entender la universalidad de su protesta, de su reivindicación. En el caso de las personas que ejercen el trabajo sexual, se han sumando múltiples asociaciones de mujeres a lo largo del mundo, primordialmente a favor de los derechos de esta población, que luchan por la reivindicación del trabajo, siendo dirigidas todas las reclamaciones al Estado por ser el protagonista que garantiza su cumplimiento, así mismo como de la comunidad internacional.

De otra forma, si bien los derechos han nacido a partir de reivindicaciones sociales, estos son fundamentados por la misma legitimidad moral de cada época, lo que implica que estos no pueden quedarse tan solo en un plano de aspiraciones morales, sino que deben extenderse hasta el plano legal permitiendo garantizar la exigencia del derecho reconocido y su reclamación ante el Estado y sus instituciones como protectores de los derechos ciudadanos, a su vez que es el Estado el único que en muchas ocasiones puede restituir la ausencia del derecho objeto de reclamación, en nuestro caso el derecho laboral y sus implicaciones.

\section{CONCLUSIONES}

El concepto o la idea que se tiene sobre la prostitución en Colombia y a nivel internacional se ha ido rezagando del matiz contemporáneo cuando se define la acción de prostituir como: "aqueIla a la que alguien dedica el uso de su cuerpo en la ejecución de actos sexuales a cambio de dinero" ${ }^{\prime \prime}$. Otra concepción se tiene respecto de una gran cantidad de personas que realizan el ejercicio de la prostitución, no por dinero, sino por la satisfacción de placeres carnales o pasionales. Estas concepciones se toman descartando la coerción en la ejecución de actos para prostituirse.

Es de tener en cuenta la dicotomía que se presenta en el supuesto de aceptar la prostitución como una actividad laboral, aceptada social, cultural y jurídicamente en nuestra sociedad y, por ende, las garantías que ello representa para quienes la ejercen o, por el contrario, determinar que debido a nuestra opulenta sociedad conservadora, nuestro ordenamiento jurídico, y en especial nuestra estructura cultural y social, no está preparada para aceptar estas actividades laborales (y el reconocimiento de derechos sociales) que puedan ser reconocidas estatalmente, puesto que tal concepción va en contra del orden social imperante y de las buenas costumbres ${ }^{9}$.

8. Real Academia Española. (2001). Diccionario de la Real Academia Española, 22ª edición.

9. Óp. Cit., Sentencia T-629 de 2010. 
La prostitución es una práctica social que se ha venido presentando desde tiempos inmemoriales como forma de expresar la libertad corporal de la que dispone la persona, tanto en la actividad económica que genera beneficios al individuo en una sociedad de extrema pobreza, respecto de los recursos necesarios para subsistir de forma individual o/y en forma colectiva. El problema es cuando surgen prácticas que tiendan a menoscabar la autonomía de la voluntad e independencia del sujeto obligado a realizar algún tipo de trabajo sexual, como en el caso de la persona que obliga a otra para que realice prácticas sexuales con el ánimo de lucro. Una dificultad son las buenas costumbres que están relacionadas con los dogmas religiosos y morales que se deslumbran en la sociedad, puesto que estos no permiten bajo sus postulados preexistentes el ejercicio del trabajo sexual. Pero estos sucesos referidos se ven absorbidos por el principio de pragmatismo (Tirado, 2010, p. 203) y el reconocimiento de los Derechos Humanos, establecidos desde el mismo momento en que aparece la persona humana y la sociedad.

La prostitución como actividad Ileva envuelta consigo una característica de continuidad histórica relevante ${ }^{10}$, matizada por caracteres de discriminación bien delimitados ${ }^{11}$. Conforme a ello, es que sea imperioso para el ordenamiento jurídico, ante la imposibilidad material de eliminar el fenómeno de la prostitución ${ }^{12}$, el asumir una posición formal frente a la misma.

En primer lugar, la Postura Prohibicionista ${ }^{13}$, la cual comporta el estadio de mayor intolerancia -por lo menos formal- hacia el desarrollo de la prostitución, es, al fin y al cabo, una expresión evidente de la lucha abierta del ordenamiento jurídico contra la corriente social, es decir, una ejemplificación del eterno y desesperado intento de las normas por ajustar las prácticas sociales a ciertos límites establecidos, hecho que desemboca, a su vez, en una clara evidencia de la vigencia y seriedad del problema de la ineficacia ${ }^{14}$ en los sistemas normativos.

10. Corte Constitucional. Sentencia T-620 de 1995 (M.P. Vladimiro Naranjo Mesa; del 14 de diciembre de 2005.) "En seguida, revisa el fenómeno de la prostitución en la jurisprudencia constitucional, desde al observa que dicho fenómeno es transversal a la cultura y a la historia de las civilizaciones (...)". Es decir, no responde a situaciones coyunturales, sino a una continuidad histórica.

11. Óp. Cit., Sentencia T-629 de 2010. En el caso del ejercicio de la prostitución, considera la Corte Constitucional que es necesario desarrollar un examen estricto de igualdad frente al tema de la discriminación negativa hacia el trabajo sexual, por entender esa discriminación en particular como sospechosa de inconstitucionalidad, al comprender a grupos tradicionalmente discriminados irrazonablemente.

12. Ibídem. "[En la prostitución] dada su magnitud y su impacto social, los Estados han preferido adoptar mecanismos preventivos de control, antes que medidas definitivas de erradicación. Es más, incluso en la hipótesis de una posición mayormente intolerante con el fenómeno, entiéndase postura legal prohibicionista, es difícil imaginar que se ponga fin de manera concluyente a una práctica social tan diseminada".

13. Ibídem. "El modelo prohibicionista excluye el comercio carnal, de modo que el Derecho lo contempla pero para prohibirlo y sancionarlo. En este marco son punibles todas las conductas relacionadas con el tráfico sexual, esto es, tanto la conducta sexual de la persona prostituida, como la de quien participa de la explotación económica de la actividad, mientras que los clientes suelen ser entendidos como víctimas de los anteriores. El bien jurídico protegido es la Moral Pública y las Buenas Costumbres".

14. Bobbio, N. Teoría General del Derecho, Bogotá-Colombia, Edit. Temis, 1997, p. 20 y ss. La Eficacia, entendida como uno de los criterios de valoración de la norma jurídica. 
Por otro lado, el modelo normativo Abolicionista ${ }^{15}$, que vendría a figurarse como un grado por debajo del prohibicionismo en cuanto al nivel de intolerancia del ejercicio de la prostitución, implica aún la no asimilación legal del fenómeno, no obstante sin prohibirla de manera frontal, es decir, sin hacer regulación positiva alguna respecto de esta, combatiendo no obstante el resto de actividades derivadas o relacionadas, a fin de combatir la proliferación de la práctica.

En tercer lugar, la Postura Reglamentista ${ }^{16}$ es la puerta de entrada hacia la asimilación legal del ejercicio de la prostitución como inextinguible de la sociedad, aceptando de paso la ineficacia de las normas prohibicionistas, conforme a las prácticas sociales. Es, en todo caso, el punto de partida para el abandono del formalismo moralista en fenómenos como la prostitución y la acogida entusiasta del realismo pragmático en torno al tema.

Por último, la Postura Laboral ${ }^{17}$ es la aceptación total y absoluta del fenómeno de la prostitución, bastando esta para ser la carta de dimisión tácita del ordenamiento jurídico ante el ejercicio de la prostitución como práctica social recurrente e inextinguible en la sociedad. Es, en otras palabras, la resignación absoluta y la aceptación de la ineficacia de las normas, para moldear prácticas sociales tan arraigadas al cúmulo social.

Es llamativo, sin embargo, el hecho de que conforme al estudio de derecho comparado realizado por la Corte Constitucional en la T-629 de 2010, se hace evidente que los ordenamientos jurídicos y las sociedades consideradas como más desarrolladas, o de primer mundo, adopten en su gran generalidad una postura reglamentista, lo cual sería un importante indicio de la lógica inherente al desarrollo lineal de la regulación respecto a este tipo de prácticas sociales, de complejo desarrollo - cabe precisar- por parte de la normatividad. Por otro lado, no sería de extrañar que consecuencialmente con este desarrollo lineal y coherente a la lógica sea la postura laboral, es decir, de adoptar como una labor u oficio más el desarrollo del fenómeno de la prostitución, la que termine por imponerse en la gran mayoría de ordenamientos jurídicos, otorgando incluso -contrariamente al prohibicionismo- derechos emanados del ejercicio de la actividad.

15. Óp Cit., Sentencia T-629 de 2010. “El modelo abolicionista pretende, desde el punto de vista jurídico, la ausencia total de reconocimiento del fenómeno y de las actividades conexas por parte del orden jurídico. Lo que se elimina no es el hecho en sí de la prostitución, sino la aceptación de su existencia y, por tanto, de regulación normativa. (...) De tal suerte se excluye la punición de la actividad individual, aunque se puede perseguir la organización de negocios destinados a la prestación de servicios sexuales".

16. Ibídem. "El modelo reglamentista, (...), tiende a reconocer la prostitución como un mal social que, al no poderse combatir, debe ser regulado a fin de evitar los efectos perniciosos relacionados con la salud, el orden social, la convivencia y buenas costumbres que pudieren derivar de su ejercicio".

17. Marjam Wijers, "Delincuente, víctima, mal social o mujer trabajadora: perspectivas legales sobre la prostitución", en Osborne.Trabajador@s del sexo. Derechos, migraciones y tráfico en el siglo XX., Barcelona, Bellaterra, 2004, Citado por Mauricio Rubio, en: Viejos verdes y ramas peladas: una mirada global a la prostitución. Bogotá-Colombia, Universidad Externado de Colombia, 2010, pp. 299 y 301 en Sentencia 29 de 2010. "Este tipo de regímenes ha dado lugar recientemente a introducir un cuarto modelo a los tradicionalmente reconocidos, denominado laboral, en el cual la prostitución se valora como un trabajo más, al cual deberían aplicarse los mismos instrumentos utilizados para proteger a los trabajadores de las diferentes industrias de eventuales abusos y violaciones de sus derechos". (Cursiva fuera de texto). 
Cabe anotar que después del análisis realizado por la Corte Constitucional y llegada a la solución del caso en concreto, esta ha plasmado unos principios o, mejor dicho, un punto de partida que permitiría pasar de una mezcla de modelos normativos a un modelo legalista ${ }^{18}$ o laboralista, siempre y cuando el legislador consagre y perfeccione la normatividad referente a los aspectos de la prostitución. Esta conclusión se analiza bajo los siguientes aspectos: (i) que el ejercicio de la prostitución no está prohibida en el ordenamiento jurídico (constitucional y legal); (ii) que la misma corte considera que el legislador está facultado por su carácter creacionista de legalizar o no el ejercicio de la prostitución (carácter democrático ${ }^{19}$ ); (iii) que no existe impedimento respecto a las buenas costumbres, en cuanto estas están contenidas y fundamentadas en la moral constitucional, que no la prohíbe; (iv) que indudablemente es un hecho cierto en la sociedad y que poco a poco el derecho y la sociedad deberá aceptar tal suceso, principio de pragmatismo; (v) que es menester reconocer la legalidad del ejercicio de la prostitución para que se desarticulen las organizaciones criminales; (vi) lo más importante es que indudablemente se deben reconocer, como lo ha hecho la comunidad internacional, los Derechos Humanos de las personas que ejercen el trabajo sexual, Bloque de Constitucionalidad; (vii) que por ser una actividad económica el Estado hace presencia, no solo determinando los aspectos alrededor del ejercicio de esta actividad sino también en su interior, ya que el Estado recauda tributación y en contraposición los trabajadores sexuales deberían recibir derechos sociales, culturales y económicos (somos socios del Estado, no ajenos a este); y (viii) que la libertad, voluntad, dignidad, igualdad, autonomía e independencia son los derechos que permiten limitar la injerencia del Estado en la esfera física y sicológica de la persona humana, por tal razón esta puede decidir si dispone de su cuerpo como medio para ejercer el trabajo sexual.

El fenómeno de la prostitución en Colombia ha sido objeto de tratamiento directo e indirecto por distintas políticas públicas ${ }^{20}$ a través de su historia, las cuales han oscilado estrictamente entre la represión y la mera tolerancia reglada ${ }^{21}$. En el caso de la primera, penalizando directamente el objeto del ejercicio de la prostitución y, en la segunda, reglamentando los temas incidentales a las prácticas de prostitución, sin comprometer concepto alguno respecto al objeto principal de estas significando, a fin de cuentas, la intervención directa de las autoridades sobre el fenómeno de la prostitución, únicamente para sancionar su ejercicio en el desarrollo de políticas públicas de orden represivo, así como la intervención eminentemente indirecta e incidental respecto de la práctica social del comercio sexual, tratándose del desarrollo de políticas públicas de tolerancia reglamentista.

18. OP Cit., Tirado, M. pp. 209-210.

19. Véase, Aguilar, E. (2008) Alexis de Tocqueville-Una Lectura Introductoria. Buenos Aires: Edit. Sudamérica.

20. Óp. Cit., Tirado, M. p. 201. "[L]a política pública se puede entender como un conjunto de sucesivas iniciativas, decisiones y acciones del régimen político que involucran simultáneamente o secuencialmente una o varias instituciones estatales frente a situaciones sociales problemáticas y que buscan la resolución de las mismas o llevarlas a niveles manejables".

21. Urrego, M. La prostitución en Bogotá: una realidad eclipsada por la moral en Placer, dinero y pecado: Historia de la prostitución en Colombia, Bogotá: Ed. Aguilar. 
Es por ello que la implementación de una política pública depende de la clase de intervención que pretendieren realizar las autoridades, ya sea a modo de orientadores absolutos de las prácticas sociales y feroces guardianes de la moral pública, o a modo de regladores y vigilantes de unas justas proporciones en ciertas conductas sociales, consideradas desagradables para la colectividad.

Consecuentemente con lo anterior, nunca se ha recurrido a una política pública en Colombia destinada hacia la legalización o reconocimiento abierto del comercio sexual como actividad reiterada en la sociedad, es decir, no se ha considerado el instituir el ejercicio de la prostitución como un trabajo legítimo, fuente de derechos y obligaciones, de orden social y económico, desconociendo así, en principio, el pragmatismo en materia de políticas públicas imperante en la gran mayoría de sociedades desarrolladas y negándose, de igual manera, a lo que resulta evidente a la luz de los resultados: la imposibilidad material de extinguir la prostitución como fenómeno social en el corto o mediano plazo ${ }^{22}$.

Es debido a lo anterior que las políticas públicas en Colombia, relativas a la materia del comercio sexual, han estado orientadas en la contemporaneidad fundamentalmente hacia fines criminológicos ${ }^{23}$, sanitarios y urbanísticos entre $\operatorname{otros}^{24}$, es decir, a penalizar desde una perspectiva prohibicionista ciertas formas y expresiones del comercio sexual en particular, consideradas más ofensivas por la colectividad social ${ }^{25} \mathrm{y}$, a su vez, orientadas a reglar ciertos aspectos incidentales, derivados o concurrentes al ejercicio de la prostitución (Cámara de Comercio, 1991, P. 53).

Es por ello que se hace loable el explicitar que: en Colombia actualmente impera un sistema mixto de políticas públicas, determinadas por un ordenamiento jurídico y por las distintas actuaciones de las autoridades, que no reconocen el fenómeno de la prostitución directamente sino en ciertos aspectos y tras la persecución de ciertos fines. Lo cual es bien evidenciado por la Corte Constitucional al estudiar la normatividad referente al tema ${ }^{26}$.

22. Cámara de Comercio de Bogotá. La prostitución en el centro de Bogotá, censo de establecimientos y personas: Análisis socioeconómico, Bogotá D.C., 1991, p. 53.

23. MEJÍA OCHOA, William, Prostitución femenina, negocio y marginalidad. Realidades y alternativas en el eje cafetero colombiano, Solidaridad Internacional Colombia, Bogotá D.C., 2003, p. 9. "Durante los últimos 40 años la única fuente de información cuantitativa disponible sobre la prostitución en Colombia ha sido la recolectada y publicada por la Policía Nacional en su revista anual Criminalidad".

24. Óp. Cit., Urrego, M. p. 197. "[L]as prostitutas solo se encuentran en las estadísticas de las enfermedades venéreas, en la legislación sanitaria, en las campañas antialcohólicas y en los códigos de policía".

25. Óp. Cit., Sentencia T- 629 de 2010, pp. 33-34. "En el Código Penal Colombiano se pueden reconocer un conjunto de delitos que representan formas de reprimir parte de las formas comerciales en que la prostitución tiene lugar". "Inducción a la prostitución" (art. 213); "Proxenetismo con menor de edad" (art. 213- A); "Constreñimiento a la prostitución" (art. 214); "Prostitución de menores" (art. 217);"Explotación sexual comercial de persona menor de edad" (art. 217-A);"Pornografía con personas menores de 18 años" (art. 218); "Turismo sexual" (art. 219); "Utilización o facilitación de medios de comunicación para ofrecer actividades sexuales con menores de edad" (art. 219 A); "Omisión del deber de denuncia" (art 219-B).

26. Óp. Cit., Sentencia T-629 de 2010, p. 38 "En definitiva, desde el Derecho penal se recoge un modelo prohibicionista que opera con la punición de todas las conductas destinadas a llevar a otro al ejercicio de la prostitución, sea que se 
Igualmente, es bien sabido que la mixtura de políticas en materia de comercio sexual ha fracasado rotundamente ${ }^{27}$, y los seres humanos involucrados en el mundo de la prostitución se hallan en una situación de mayor vulnerabilidad conforme al marco de ilegalidad o de vacío en que se halla su actividad ${ }^{28}$. Indefinición política y consecuente indefinición normativa en torno a la temática del ejercicio de la prostitución, que es el elemento fundamental del problema jurídico planteado a la Corte Constitucional en la Sentencia T-629 de 2010 ${ }^{29}$.

Debido a esto es que el primer punto que debiera ser tratado conforme a una política pública integral respecto al ejercicio de la prostitución, debe ser el de definir de manera clara la posición de la prostitución voluntaria en el marco jurídico y en panorama político, lo cual no puede iniciar de otra manera que con el reconocimiento explícito del fenómeno en la sociedad por parte de las autoridades ${ }^{30}$. Situación que daría cabida a una progresiva asimilación de la prostitución a la actividad laboral y que abriría con ello el camino hacia el pragmatismo político en materia de comercio sexual, sin perjuicio por ello de sostener ciertas limitaciones difícilmente transables con la colectividad social ${ }^{31}$.

También el Estado, frente a su responsabilidad como garante ${ }^{32}$ de la protección de los derechos sociales, económicos y culturales conexos con los derechos fundamentales, está obligado a proporcionar la protección adecuada a los miembros de la sociedad, con fundamentos en todas aquellas disposiciones de tipo constitucional, como: la Carta Fundamental y los tratados internacionales ratificados por Colombia; Bloque de constitucionalidad ${ }^{33}$

obligue por la fuerza o se convenza por la inducción, sea que se actúe sobre personas sin capacidad de discernir o decidir, o frente a aquellas que pretenden actuar libremente. (...). Puede observarse entonces que, conforme al Derecho de policía (...) [s]e sigue así un modelo reglamentista, dirigido a proteger la salud pública, el orden social, la convivencia entre quienes practican el oficio y el resto de la colectividad, así como a la ubicación geográfica de la actividad como forma de reducir su impacto".

27. Óp. Cit., Cámara de Comercio de Bogotá. p. 49. "El panorama descrito contrasta con la ninguna o muy poca actividad preventiva o correctiva por parte de las autoridades competentes: son débiles, aislados y esporádicos algunos de los esfuerzos que se hacen, y que por no ser sistemáticos y concretos, generan falsas expectativas en la población (...) Desgraciadamente, las acciones más visibles están constituidas por medidas represivas (...) que apuntan a la forma y no al fondo del problema" (subrayado fuera de texto).

28. Ibíd., p. 19 "[L]a legislación vigente lleva en la práctica a una indefinición jurídica sobre la prostitución. Así, el fenómeno no se acepta explícitamente, tampoco se atiende ni se combate y el escaso tratamiento que se le da ni siquiera afecta algunas de sus formas y mucho menos el fondo del problema".

29. Óp. Cit., Sentencia T-629 de 2010, p. 46 “2.5. Licitud o ilicitud de la prostitución"

30. Óp. Cit., Cámara de Comercio de Bogotá. p. 53. "[Es preciso] impulsar un proceso de reconocimiento explícito de que la prostitución existe, que es un fenómeno que se ha desbordado, que no es posible acabarlo a corto plazo, que está generando efectos negativos importantes y que se requiere una acción directa e inmediata."

31. Ibíd., p. 53. "Los efectos colaterales [del ejercicio del comercio sexual], como son la drogadicción, el consumo y tráfico de drogas, la delincuencia, la corrupción de menores y la violencia, entre otros, sí deben ser objeto de acciones represivas por parte del Estado, para minimizar sus consecuencias negativas."

32. Actividad no únicamente de abstención del Estado, sino también de intervención.

33. Véase, Arango, M. El Bloque de Constitucionalidad en la Jurisprudencia de la Corte Constitucional Colombiana, en http://www.icesi.edu.co/esn/contenido/pdfs/C1C-marango-bloque.pdf. Precedente judicial, 2004. Véase, UPRIMNY 
en estricto sensu o lato sensu, ya que la primera consagra todos los derechos y fines del Estado, que deben ser cumplidos de manera prioritaria por el juez ${ }^{34}$, a quien le corresponde la eficacia ${ }^{35}$ de los derechos, en atención a evitar un perjuicio irremediable e inseguridad jurídica. El segundo permite que la creación, interpretación y aplicación de la normatividad constitucional y legal se realice con fundamento en aquellos principios y normas internacionales que adquieren rango o fuerza constitucional, (gracias a que la Constitución es un catálogo abierto y amplio de derechos) por medio de las normas de remisión que esta consagra, como son los artículos 53, 93, 94, 214, entre otros. Concluimos en que el Estado no solo es responsable por mandato constitucional, ordenamiento interno, sino que también es responsable a nivel internacional por la protección de los derechos fundamentales, económicos, sociales, culturales y hasta colectivos. Pacta sunt ser vanada de Buena fe y la obligatio es iuris vinculum quo nesessitateadstringimuralicuissolvendaeirei (...) relación entre el Estado frente al particular. Es decir, los pactos son para cumplirlos de buena fe (constitución y tratados o convenciones internacionales sobre derechos humanos y demás), de donde nacen obligaciones que son vínculos de derechos que constriñen [al Estado] en el cumplimiento de una prestación [dar, hacer o no hacer] en favor de otro [el particular]. Esto debido a que el incumpliendo de la obligaciones por parte del Estado no es una carga que tenga que soportar el particular.

La sentencia referenciada es sumamente importante en cuanto establece un precedente judicial y además abre las posibilidades de una legalización reglamentada en el ejercicio de la prostitución. Providencia de gran significado respecto a los Derechos Humanos.

YEPES, Rodrigo, "El Bloque de Constitucionalidad en Colombia - Un Análisis Jurisprudencial y un Ensayo de sistematización doctrinal", en: Compilación de Jurisprudencia y Doctrina Nacional e Internacional, Volumen I, Oficina del Alto Comisionado de las Naciones Unidas para Colombia, 2001.

34. Corte Constitucional. Sentencia T-406 de 1992 (M.P. Ciro Angarita Barón; 5 de junio1992).

La efectividad de los derechos le pertenece de forma prioritaria a los jueces, a falta de pronunciamientos por parte del legislador. Al juez, en especial el constitucional, es a quien le corresponde por mandato de la Carta Superior, efectivizar los derechos fundamentales de aplicación inmediata y los que no lo son. Aquellos derechos que no son fundamentales y no son de aplicación directa, pasan a ser fundamentales y de cumplimiento directo, cuando contienen: (i) relación o concordancia con los principios de la Constitución y; (iii) además, una conexidad estrecha con derechos fundamentales. Estos que para que se consideren fundamentales deben comprender los siguientes requisitos: (i) contenido esencial; (ii) relación directa con los principios de la Constitución y: (iii) ser de carácter de aplicación directa. Fundamento del que carecen muchas veces los derechos económicos, sociales y culturales, razón por la cual, para su efectividad dependen de una observancia de posibilidades económicas e igualdad social. El juez al considerar la protección de este tipo de derechos, responde a un interés general y a una conjugación o relación entre la Constitución - principios y normas, la ley y los hechos, para poder así proteger y efectivizar los derechos, tutelando los fines perseguidos por el Estado Social de Derecho y la Constitución Nacional.

35. Óp. Cit., Bobbio, N. p. 20 y ss. Dentro de los criterios de valoración de una norma jurídica encontramos: (i) la justicia, si la norma jurídica es o no acorde con los principios del ordenamiento jurídico; (ii) la validez, si la norma jurídica existe o no dentro del ordenamiento jurídico y; (iii) la eficacia, que la norma sea cumplida para quienes va dirigida, criterio que es el fin último del derecho positivado. 


\section{BIBLIOGRAFÍA}

- $\quad$ Altman, D. (2006). Sexo Global. México: Edit. Océano.

- Aguilar, E. (2008). Alexis de Tocqueville. Una Lectura Introductoria. Buenos Aires - Argentina: Edit. Sudamérica.

- Arango, M. (2004). Precedente judicial. El Bloque de Constitucionalidad en la Jurisprudencia de la Corte Constitucional Colombiana. Disponible en http://www.icesi.edu.co/esn/contenido/pdfs/C1C-marangobloque.pdf., [30 de marzo de 2011].

- Bobbio, N. (1997). Teoría General del Derecho. Bogotá-Colombia: Edit. Temis. Bogotá.

- Cámara de Comercio de Bogotá. (1991). La prostitución en el centro de Bogotá, censo de establecimientos y personas: Análisis socioeconómico, Bogotá D.C.

- Corte Constitucional. Sentencia T-406 de 1992 (M.P. Ciro Angarita Barón; 5 de junio1992).

- $\quad$ Corte Constitucional. Sentencia T-620 de 1995 (M.P. Vladimiro Naranjo Mesa; 14 de diciembre).

- Corte Constitucional. Sentencia T-881 de 2002 (M.P. Eduardo Montealegre Lynett; 17 de octubre de 2002).

- Corte Constitucional. Sentencia T-152 de 2007 (M.P. Rodrigo Escobar Gil; 5 de marzo de 2007).

- $\quad$ Corte Constitucional. Sentencia T-629 de 2010 (M.P. Juan Carlos Henao Pérez; 13 de agosto de 2010).

- Kara, S. (2010). Tráfico Sexual. El negocio de la esclavitud moderna. Madrid: Edit. Alianza Editorial.

- Levvit, S. y Dubner, S. (2010). Super Freakonomics. Enfriamiento global, prostitutas patrióticas y por qué los terroristas deberían contratar un seguro de vida. Bogotá: Edit. Debate.

- Manier, B. (2007). Cuando las mujeres hayan desaparecido. Madrid: Ediciones Cátedra, Universidad de Valencia.

- Martínez, A. y Rodríguez, P. (2002). Placer, dinero y pecado. Historia de la prostitución en Colombia. Bogotá: Ed. Aguilar.

- Mejía, W. (2003). Prostitución femenina, negocio y marginalidad. Realidades y alternativas en el eje cafetero colombiano, Solidaridad Internacional Colombia. Bogotá D.C.

- Real Academia Española. (2001). Diccionario de la Real Academia Española. 22a edición.

- Rubio, M. (2010). Viejos verdes y ramas peladas: Una mirada global de la prostitución. Bogotá: Universidad Externado de Colombia. 
- $\quad$ Tirado, M. (2010). Comercio Sexual - Una Mirada desde la Sociología Jurídica. Lima - Perú: edit. Instituto Internacional de Derecho y Sociedad.

- Uprimny, R. (2001). El Bloque de Constitucionalidad en Colombia - Un Análisis Jurisprudencial y un Ensayo de sistematización doctrinal. En: Oficina del Alto Comisionado de las Naciones Unidas para Colombia (Eds.) Compilación de Jurisprudencia y Doctrina Nacional e Internacional. Bogotá.

- Urrego, M. (2002). La prostitución en Bogotá: una realidad eclipsada por la moral en: Placer, dinero y pecado: Historia de la prostitución en Colombia. Bogotá: Ed. Aguilar.

- Vattimo, G., Mardones, J. \& otros. (1994). En torno a la posmodernidad. Bogotá: Ed. Anthropos. 